\title{
Understanding the Behavior of Sharing Information of Wechat Users: An Integrated Model
}

\author{
Haiqing $\mathrm{Bai}^{1, \mathrm{a}}$ and Sixu $\mathrm{He}^{2, \mathrm{~b}^{*}}$ \\ ${ }^{1}$ School of Journalism and Communication, Xiamen University, Xiamen, 361005, China \\ ${ }^{2}$ School of Management, Xiamen University, Xiamen, 361005, China \\ ${ }^{*}$ The corresponding author
}

Keywords: Wechat; Sharing information; Rational action theory; Trust

\begin{abstract}
In this paper we propose a holistic view on the behavior of sharing information of Wechat users. We posit not only factors that have been studied before (traditional social factors based on rational action theory) but also social network factors (i.e., trust and habit of users for their sharing information in Wechat) could influence the behavior of sharing information. This study attempts to contribute to the understanding of information sharing behavior in Wechat context.
\end{abstract}

\section{Introduction}

In 2011, as an instant social tool, Wechat attracted public eye and captured people's hearts as surprisingly sudden as lightning. It became one of the hottest mobile communication tools with the highest utility rate. Wechat is sort of mobile communication software, which can send messages, pictures, videos, texts and take single-chats or group-chats by phone network. Since the day it was invented, the number of users had exceeded 100 million in just 14 months, and then reached 300 million in nearly 24 months, and 33 months later, it had more than 600 million users. Apart from Wechat's advantage of effectively integrating various social chains such as LBS making friends, phone contacts, QQ etc., the reason why Wechat becomes increasingly attractive to its users also greatly lies in the innovation of communication mode based on user experience. On the one hand, as a social platform it mainly focuses on "strong relationship", Wechat reduces maintenance costs among the public, makes the emotional connection among people closer to face-to-face communication by technical support of the comprehensive application of text messages, network audio and video technology in contemporary society, which increasingly pursues harmonious interpersonal interaction. On the other hand, Wechat's "public communication", namely the attribute of its mutual interlacement of public information and private dissemination makes the formation of users' information sharing intention become more smooth and powerful.

Based on the previous studies of behavior theory and information sharing behavior, this paper views Wechat as the research object, and builds a model of impact factor on Wechat users' information sharing, and investigates the model. This study aims to enrich the behavior research in Wechat context, and to offer theoretical guidance for enterprises' marketing behaviors.

\section{Literature Review}

Research of Relative Wechat. Since Wechat has invented for just more than 3 years, many studies have discussed the Wechat. For example, they focused on Wechat's advantages comparing with other traditional media, Weibo, M-talking and some similar tools, Wechat's propagation mode, the reason for the rise of Wechat, Wechat's marketing or propagation value, implementation means, new opportunities for "we media" brought by Wechat. Although their research perspectives are different from users' information sharing intention, some of the listed contents about Wechat's features can help us acquaint with Wechat's sharing attributes in an indirect way. For example, Zhang (2013) points out that the combination of Wechat and smart phones enlarges the function of Wechat get, and a large number of information and knowledge also disseminate extensively through the Wechat [1]. From the 
perspective of Lasswell's " $5 \mathrm{~W}$ model”, Dang (2012) illustrates the propagative characteristics of the Wechat from user's characteristics, emotional needs, habits and other angles. These characteristics can also be used for reference in emotional viscosity, received accurate information from companies and other aspects of Wechat users' information sharing [2]. Furthermore, Fang (2012) discusses Wechat's low use cost, various communication methods, more private and simple usage, which in turn shows how Wechat meets user's emotional communication, mutual knowledge requirements and the desire to get something new on emotional level [3].

It seems that the current academic research on Wechat is still in its early stage, which mainly focuses on value cognition and application evaluation of Wechat, while the systematic and completed theoretical framework has not been formed yet. Also, the research on Wechat's information sharing is also quite few.

Information Sharing Behavior. Information sharing, as a social exchange behavior, becomes increasingly efficient and feasible in virtual community, which is growing stronger and more mature. Some studies view information sharing as an integral part of effective knowledge management, and suggest that it is a process for an individual passing his/her professional knowledge, insight and understanding to another, so that the information receiver can apply it to the tasks confronted [4]. Some viewpoints suggest that sharing behavior and intention could occur directly in daily communication, as well as indirectly in all kinds of social networks [5]. However, some studies have different viewpoints. For example, Huysman and Wulf (2006) argue that people are not willing to share information under all situations [6], whereas Wasko and Faraj (2005) suggest that some individuals more tend to share information than others [7]. That is to say, people don't understand the reason why people are willing or unwilling to share information.

Fortunately, there are many studies related to knowledge and information sharing. Their focuses are on factors of knowledge sharing behavior, such as domain of information sharing, components of motivation, and impacts of information sharing on intention to use different systems or products. For example, Zhao (2013) points out that motivation of individual knowledge sharing is not only for economic or non-economic benefits, but also out of respect for sharing customs or rules and obedience as well as a sense of moral responsibility, in addition to the motivation of knowledge sharing confirmation, which includes personal interests, obeying rules, perceived achievement, relationship building, collective emotion and responsibility these five factors. For those Chinese group or organizations, which have formed the knowledge sharing culture and atmosphere, the ethical motivation of its members' knowledge sharing is more prominent [8].

On factors of knowledge sharing, Hsiu (2007) integrates motivation into Rational Action Theory and discusses how the internal and external factors play critical role in knowledge sharing attitude and intention of employees in the organization. Results show that reciprocal interests, self-efficacy of knowledge, and pleasure brought by helping others relate to employee's knowledge sharing attitude and behavior significantly, except for the expected organizational rewards [9]. In the intention of product use, Hsu et al. (2008) study effects of altruism, expected reciprocal benefit and relationship, trust and reputation on blog using attitude. Results show that only the altruism and reputation play a significant role, that is to say, people hope to use blog to help others by sharing knowledge, and then gain higher reputation [10].

Moreover, those studies focusing on system use are useful to understand information sharing. For example, Gefen et al. (2003) integrate trust into research on the basis of Technology Acceptance Model (TAM) when study users' online shopping behavior, and demonstrates that trust and some factors of TAM also play an important role in explaining users' adoption intention of online shopping behavior. Trust means that the seller does not profit through cheating, websites have a convincing safety guarantee, online shopping situation is not different from shopping experience in physical stores, and shopping interface is ease of use [11]. Limayem et al. (2007) analyzes habit has negative moderation in relationship of intention and continuous information system use [12]. Van Raaij et al. (2008) extend subjective norms, individual innovation in information technology domain and computer anxiety to TAM2 model, and demonstrate the perceived usefulness directly affects the use of 
Virtual Learning Environment. Besides, perceived ease of use and subjective norm only have indirect impact on the use of the VLE via perceived usefulness, and perceived ease of use is directly affected by individual innovation and computer anxiety [13].

These studies may have favorable reference value to the study of information sharing and Wechat information sharing intention.

\section{Research Model and Hypothesis Development}

Social psychologist Harry Triandis not only believes that social factors and emotion play a critical role on impacting behavior intention, but also stresses the importance of the past behaviors impacting continuance usage. Triandis (1977) insists that the occurrence of actual behavior is caused by habits, and facilitating conditions jointly, and attitude, social factors and emotion together form the intention. Thus, Trandis comes up with the theory of interpersonal behavior [14]. Based on this perspective, we consider the roles of the supporting of software and hardware resources to the convenience for users, and the inertia which occurs when users use the system. Users' sharing behavior in Wechat context is similar to users' behavior of using information system. Therefore, the study supposes facilitating conditions and habit as the main independent variable which influences the intention of sharing information.

Moreover, users' information sharing behavior benefits from the successful use of the information system, while the adoption and use of information systems depend on user's continuance usage. As for system adopt model, a famous theory is Technology Acceptance Model (TAM) put forward by Davis (1989), in which he argues that usefulness and perceived usability of perceived system form the use attitude, while perceived usefulness and attitude determine behavioral intention together, and behavioral intention determine the system use [15]; Icek Ajzen (1991) proposed the Theory of Planned Behavior (TPB) on the basis of the Theory of rational Behavior (TRB), in which he insists that the behavioral attitude, subjective norm and perceived behavior control are the three determinants of behavioral intention, and then behavioral intention determines behavior directly [16]. In addition, many scholars conduct further critical and expanded research on users' continual using behavior on the basis of the classic theory model.

Due to the special attributions of Wechat comparing with other similar products, for example, it can bind with QQ and phone contacts, so it's easier to develop users' habit of using it. Following this idea and combining with the theory of planned behavior, this study takes "subjective norm" as independent variable which affects the habits. On that basis, considering that users will pay more attention to privacy and security of system with the development and progress of science and technology, this study also uses "perceived trust" as an independent variable which affects the habits.

To sum up, this paper is based on the theory of planned behavior and Triandis's interpersonal behavior theory and builds the model of Wechat users' information sharing intention. (Fig. 1)

Facilitating conditions refer to the supporting degree of the existing associated equipment to user using the system when he/she adopt a kind of product or technology. Technology acceptance and use of the unified theory (UTAUT), Triandis's theory of interpersonal behavior and Venkatesh et al. (2012) have proved that the facilitating condition is one of the determinants of actual behavior [17]. Applying this concept to Wechat, this study argues that facilitating conditions mainly include the cost of time and money, convenient information search, usability of equipment and availability of the Internet, which are needed in users' information sharing behaviors. Smart phones, Internet, Wechat user experience and function push are also speeding and extending Wechat users intention to share information. So here is the first hypothesis:

H1: Facilitating conditions positively influences users' intention of sharing information. 


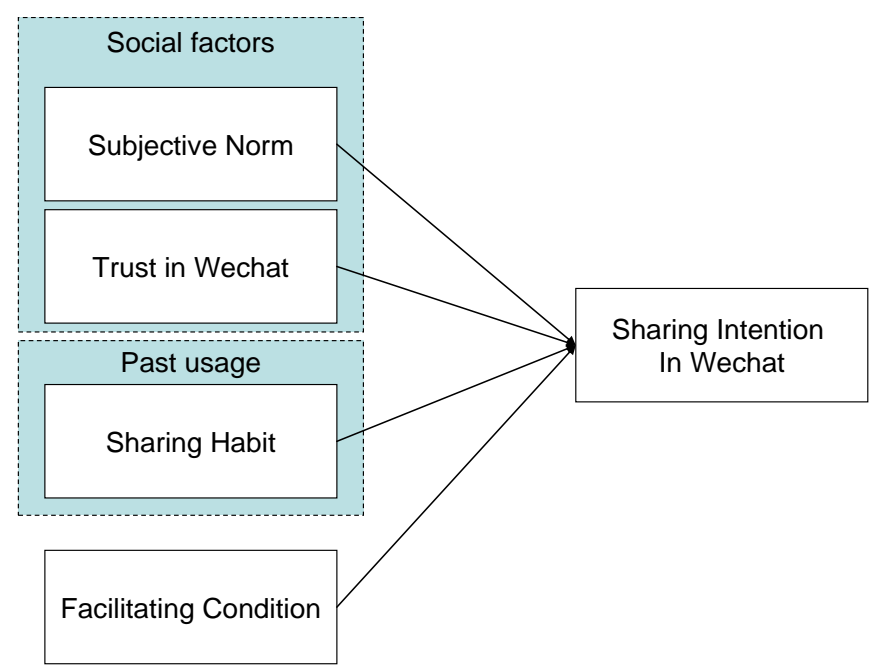

Figure 1. Research model

Habit refers to the extent to which people tend to perform behaviors (use IS) automatically because of learning. Limayem, Christy, and Cheung (2007) suggested that when an individual's habit of implementing a specific behavior enhanced, intention's explanatory ability to continuous usage behavior would become weaken correspondingly. Thus, habit plays negative moderating effect in the relationship between behavior and intention [12]. Given this substitution effect and scholars' studies of the past, as well as the convenience and efficiency of Wechat sharing and perceived trust among Wechat users which is different from other information systems and virtual community, we predict that Wechat users' information sharing habit can further enhance the power of influential factors of sharing intention, such as facilitating conditions in this study. So the second hypothesis of this study is as follows:

H2: Sharing habit is positively related to users' intention of sharing information.

Trust is especially important to information sharing behavior in virtual community. Bock, et al. (2005) argue that individuals who are of mutual trust are more willing to share their own ideas and comprehensive information [18]; Prior studies have found that interpersonal trust plays an important role in creating good atmosphere of knowledge sharing in organizations or a group of people, and trust can creates and maintains the exchange relationship, which in turn leads to the high quality knowledge sharing behavior [19]. In contrast, since the source of the Wechat friends is generally from the QQ friends, phone contacts or friends who have passed validation, the friends in Wechat have "strong relationship" with a sense of security and privacy. Therefore, under this cohesive relationship, users have a strong sense of perceived trust to use Wechat to share information. The more the users trust this behavior, the less they evaluate other factors, in other words, users will use Wechat to share information unconsciously and form the corresponding habit. So the third hypothesis of this study is as follows:

H3: Trust in Wechat is positively related to users' intention of sharing information.

Subjective norm refers to the perceived social pressure to engage or not to engage in a behavior. In TRA model and TPB model, behavioral intention partly depends on the impact of subjective norms [13]. This idea can also be applied to Wechat information sharing behavior. That is because the ideas of important groups usually cannot be wrong in the eyes of users in general, so individuals tend to rely on these views unconsciously and integrate them into their own logic system. So when most of relatives and friends think use Wechat to share information is useful and they do implement it, they will feel this behavior is helpful in certain. On the other hand, when users perceive that relatives and friends who are considered important are sharing information and communicating by Wechat, they will worry that it could weaken or break their relationships if they not engage in these behaviors. So they have to obey this behavior phenomenon and take part in Wechat information sharing behavior together. 
Combining above viewpoints with practical situation, with the increasing numbers of Wechat users, the number of individuals who are prone to be affected will also enhance. When individuals see the people around them are using Wechat to share information, they will also get into the habit of using Wechat to share information more automatically. So the forth hypothesis of this study is as follows:

H4: Subjective norm is positively related to users' intention of sharing information.

\section{Proposed Research Method}

We plan to conduct a survey to collect data and test hypothesis. The first step is to design questionnaires and scales. Because relative variables (trust, habit, facilitating condition, and subjective norm) have mature scales which are used in high frequency have been translated in the area of information system usage, a few wording of the items will be adjusted and can fit in this study. The Questionnaire is composed of three parts: basic information of Wechat usage, scale, and basic personal information. All items were measured with a five-point Likert-type scale (ranging from "strongly agree" to "strongly disagree"). The second step is to collect data. In the light of those whose sharing behavior in Wechat context occur by mobile phone or network, our questionnaires should be issued in the form of electronic questionnaire. We plan to issue questionnaires through a third party, namely the Questionnaire Star for collection and preservation. The third step is to test hypotheses. The method of structure equation model will be adapted to conduct test hypotheses.

\section{Discussion and Future Works}

In summary, this paper addressed an important issue for the behavior of sharing information in Wechat context. Traditional social factor (e.g., subjective norm and trust), past usage (e.g., habit), and facilitating codition are integrated into a framework model from a new viewpoint of diffusion theory. To evaluate our model, we developed four hypotheses in the context of Wechat. In next step, we will test those hypotheses, and this study attempts to contribute traditional rational action theory.

\section{Acknowledgements}

This research is funded by the Principal Fund of Xiamen University: the empirical research on the factors influencing the loyality of online shoppers (20720151117)

\section{References}

[1] Zhang, Y. (2013). Timeliness of Marketing Mode and Achievement of Strategy from the Perspective of Communication. China Publishing Journal, (16), 18-20.

[2] Dang, H. Q. (2012). Deconstruct the Information Transmission Model from the Perspective of Communication. Southeast Communication, (7), 71-72.

[3] Fang, Z. X., \& Cai, L. T. (2012). The Rise of Micro-Letter from the Perspective of Communication. The Guide of Science \& Education, (5), 219-220.

[4] Bock, G. W., \& Kim, Y. G. (2001). Breaking the myths of rewards: An exploratory study of attitudes about knowledge sharing. Pacis 2001 proceedings, 78.

[5] Yu, T. K., Lu, L. C., \& Liu, T. F. (2010). Exploring factors that influence knowledge sharing behavior via weblogs. Computers in Human Behavior, 26(1), 32-41.

[6] Huysman, M., \& Wulf, V. (2006). IT to support knowledge sharing in communities, towards a social capital analysis. Journal of information technology, 21(1), 40-51.

[7] Wasko, M. M., \& Faraj, S. (2005). Why should I share? Examining social capital and knowledge contribution in electronic networks of practice. MIS quarterly, 35-57. 
[8] Zhao, S. S. (2013). Research on Employee's Motivation Model of Knowledge Sharing in the Context of Chinese Culture. Nankai Business Review, 16(5), 26-37.

[9] Hsu, M. H., Ju, T. L., Yen, C. H., \& Chang, C. M. (2007). Knowledge sharing behavior in virtual communities: The relationship between trust, self-efficacy, and outcome expectations. International journal of human-computer studies, 65(2), 153-169.

[10] Hsu, C. L., \& Lin, J. C. C. (2008). Acceptance of blog usage: The roles of technology acceptance, social influence and knowledge sharing motivation. Information \& management, 45(1), 65-74.

[11] Gefen, D., Karahanna, E., \& Straub, D. W. (2003). Trust and TAM in online shopping: an integrated model. MIS quarterly, 27(1), 51-90.

[12]Limayem, M., Hirt, S. G., \& Cheung, C. M. (2007). How habit limits the predictive power of intention: The case of information systems continuance. Mis Quarterly, 705-737.

[13] Van Raaij, E. M., \& Schepers, J. J. (2008). The acceptance and use of a virtual learning environment in China. Computers \& Education, 50(3), 838-852.

[14] Triandis, H. C. (1977). Interpersonal behavior. Brooks/Cole Pub. Co..

[15]Davis, F. D. (1989). Perceived usefulness, perceived ease of use, and user acceptance of information technology. MIS quarterly, 319-340.

[16] Ajzen, I. (1991). The theory of planned behavior. Organizational behavior and human decision processes, 50(2), 179-211.

[17] Venkatesh, V., Morris, M. G., Davis, G. B., \& Davis, F. D. (2003). User acceptance of information technology: Toward a unified view. MIS quarterly, 425-478.

[18] Bock, G. W., Zmud, R. W., Kim, Y. G., \& Lee, J. N. (2005). Behavioral intention formation in knowledge sharing: Examining the roles of extrinsic motivators, social-psychological forces, and organizational climate. MIS quarterly, 87-111.

[19] Blau, P. M. (1964). Exchange and power in social life. Transaction Publishers. 